\title{
Evaluation of Violence Against Emergency Physicians in Turkey
}

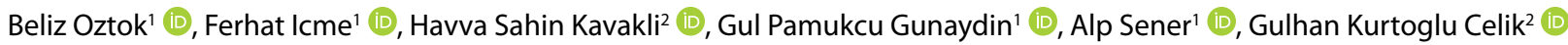 \\ 'Department of Emergency Medicine, Ankara Ataturk Training and Research Hospital, Ankara, Turkey \\ ${ }^{2}$ Department of Emergency Medicine, Yildirim Beyazit University School of Medicine, Ankara, Turkey
}

Cite this article as: Oztok B, Icme F, Kavakli HS, Pamukcu Gunaydin G, Sener A, Kurtoglu Celik G. Evaluation of Violence Against Emergency Physicians in Turkey. Eurasian J Emerg Med. 2018; 17 (4): 182-6.

\begin{abstract}
Aim: Violence against healthcare workers is most commonly experienced in emergency rooms. The present study aimed to assess the extent of increasing violence toward emergency physicians in Turkey and to define their opinions about reasons of violence.

Materials and Methods: This descriptive cross-sectional study was carried out in 2013 in Ankara, Turkey. Emergency physicians attended a questionnaire that included 25 multiple-choice questions. Emergency physicians working in training and research, university, and state hospitals were included in the study.

Results: A total of 502 emergency physicians were included in the study. Overall, 338 (67.3\%) participants were male. The number of participants who stated that they witnessed violence against physicians or other healthcare workers at least once during their career was 494 (98.4\%). In total, 414 ( $82.5 \%$ ) participants stated that they faced violence at least once. Exposure to violence negatively affected the social life of 251 (60.6\%) participants and resulted in decreased job satisfaction or interest toward their profession in 227 (54.8\%) participants. The number of participants who believed that healthcare policies affected the increase of violence against healthcare workers was 490 (97.0\%).

Conclusion: Our results indicate that violence against emergency physicians has reached very high levels and affects job satisfaction of physicians working under such circumstances.
\end{abstract}

Keywords: Violence, emergency medicine, physician

\section{Introduction}

Violence has several available definitions in literature. Michaud defined violence in a broad sense as "harmful behaviors of a party toward bodily integrity, moral integrity or property, or symbolic and cultural values of others in a reciprocal relationship" (1).

Studies on violence in a workplace indicate that the number of cases of violence in the healthcare sector is much higher than that in other sectors. Violence in the healthcare sector is most frequently seen in emergency services followed by psychiatry clinics (2). Studies also revealed that only assaults that resulted in injury are considered to be cases of violence and are reported to authorities, whereas other forms of violence are usually not reported. The actual incidence of violence is unknown owing to underreporting (2-4).

The present study aimed to assess the extent of increasing violence toward emergency physicians in Turkey and to define the reasons of this violence through their opinions.

ORCID IDs of the authors: B.O. 0000-0002-4007-005X; F.I. 0000-0001-5180-7152; H.S.K. 0000-0001-5625-8172; G.P.G. 0000-0001-8531-4591; A.S. 0000-0002-0583-2936; G.K.C. 0000-0003-1259-3694.

Corresponding Author: Gul Pamukcu Gunaydin e-mail: gulpamukcu@gmail.com 


\section{Materials and Methods}

This descriptive and cross-sectional study included 502 emergency physicians working at university hospitals, education and research hospitals, state hospitals, and private hospitals in various provinces in Turkey. A questionnaire was used to collect data. The study was conducted between April 15 and July 15, 2013 in Ankara, Turkey. The local ethics committee of Yildirim Beyazit University School of Medicine approved the study protocol. The questionnaire comprised of 25 multiple-choice questions. The number of emergency physicians in Turkey was approximately 1600 at the time of the study. Written information about the study was provided and informed consent was obtained before participants filled out the questionnaires.

The questionnaire was filled out face to face with 253 physicians working in hospitals in Ankara. Emergency physicians working

Table 1. Demographic characteristics of the physicians

\begin{tabular}{|l|c|c|}
\hline Variables & $\mathbf{n}$ & (\%) \\
\hline Job title & & \\
\hline Emergency medical assistant & 319 & 63.5 \\
\hline Specialist & 144 & 28.7 \\
\hline Assistant professor & 39 & 7.8 \\
\hline Institution & & \\
\hline State hospital & 62 & 12.4 \\
\hline Training and research hospital & 270 & 54.1 \\
\hline University hospital & 164 & 32.9 \\
\hline Private hospital & 3 & 0.6 \\
\hline
\end{tabular}

Table 2. Effects of violence on physicians

\begin{tabular}{|l|c|c|}
\hline Variables & $\mathbf{n}$ & (\%) \\
\hline I am injured & 24 & 5.8 \\
\hline I needed treatment & 69 & 16.7 \\
\hline I could not go to work & 6 & 1.4 \\
\hline I thought of quitting my job & 92 & 22.2 \\
\hline Loss of motivation & 224 & 54.1 \\
\hline Loss of job satisfaction & 227 & 54.8 \\
\hline Decrease in working quality & 221 & 53.4 \\
\hline Acute stress disorder & 124 & 30.0 \\
\hline Traumatic stress disorder & 192 & 46.4 \\
\hline Fear/panic/restlessness & 198 & 47.8 \\
\hline Sleep disorder & 181 & 43.7 \\
\hline Headache & 55 & 13.3 \\
\hline Abdominal pain & 136 & 32.9 \\
\hline Negative effects on social life & 251 & 60.6 \\
\hline Decline of trust to the administration & 167 & 40.3 \\
\hline Property damage & 37 & 8.9 \\
\hline Carrying a knife/tear gas & 88 & 21.3 \\
\hline
\end{tabular}

outside Ankara were contacted via e-mail. E-mail addresses were obtained from two emergency medicine associations in Turkey. A total of 1309 e-mail addresses were obtained, and 121 of them were incorrect. The survey was sent to the rest of the e-mail addresses. At the end of the fourth week, 134 answers were received, and in the fifth week, the questionnaire was re-sent to the physicians who did not respond. A total of 249 responses were received in the 10 th week. The e-mail response rate was $20.9 \%$.

\section{Statistical analysis}

Normally distributed variables for age and working period in the health sector were assessed using the Shapiro-Wilk test. Descriptive statistics for variables that were not normally distributed were presented by median and interquartile ranges (IQR). Demographic characteristics such as gender, job title, the number of patients seen during a shift in the emergency room, and the distribution of responses given to questions were presented as numbers ( $n$ ) and percentages (\%). Chi-square test was used to analyze the relationship between exposure to violence and variables including gender, job title, and the institutions of occupation. Similarly, comparisons between the stated questions were analyzed using the chi-square test. The relationship between the frequency of exposure to violence and the duration of profession was evaluated using the Kruskal-Wallis test. Pairwise comparisons were performed using Bonferroni correction to determine the group causing the difference according to the Kruskal-Wallis results. IBM Statistical Package for the Social Science for Windows, v.21.0. (IBM Corp., Armonk, NY, USA) and MS Excel 2007 were used for statistical analysis and calculations. $\mathrm{p}<0.05$ was considered to be statistically significant.

\section{Results}

A total of 502 emergency physicians were included in the study, of which $338(67.3 \%)$ were males and 164 (32.7\%) were females. The median age was 31.0 years $(\mathrm{IQR}=7.0)$. Table 1 presents the participants characteristics.

Security guards were present in $95 \%$ of the emergency rooms where the participants worked, whereas security was insufficient as thought by $89 \%$ of the participants. Security cameras were available in $93.4 \%$ of the institutions; however, they were insufficient as thought by $76.5 \%$ of the participants. Security officers were easily accessible in $66.5 \%$ of the institutions; $97 \%$ of the security officers did not have a metal detector.

A total of 494 (98.4\%) individuals stated that they witnessed violence against doctors or health professionals at least once during their careers. The number of individuals who stated that they were a victim of violence during their profession was 414 (82.5\%).

No statistically significant relationship was observed between sex and exposure to violence $\left(x^{2}=0.01 ; p=0.973\right)$. There was a statistically significant difference between exposure to violence and job title $\left(X^{2}=11.941 ; p=0.018\right)$. Emergency medicine physicians had been exposed to violence more than the other groups. Exposure to violence was significantly higher in the training and research hospitals than in other institutions $\left(x^{2}=22.236 ; p=0.000\right)$. 
Table 3. Demographic characteristics of the aggressors

\begin{tabular}{|c|c|c|}
\hline Variables & $\mathbf{n}$ & (\%) \\
\hline \multicolumn{3}{|l|}{ Gender } \\
\hline Male & 336 & 81.6 \\
\hline Female & 76 & 18.4 \\
\hline \multicolumn{3}{|l|}{ Age } \\
\hline $15-25$ years & 92 & 22.3 \\
\hline $25-40$ years & 232 & 56.3 \\
\hline $40-55$ years & 84 & 20.4 \\
\hline$>55$ years & 4 & 1.0 \\
\hline \multicolumn{3}{|l|}{ Socio-economic level } \\
\hline Higher & 170 & 41.3 \\
\hline Lower & 240 & 58.7 \\
\hline \multicolumn{3}{|l|}{ Education } \\
\hline Primary school & 69 & 16.7 \\
\hline High school & 54 & 13.1 \\
\hline University & 52 & 12.7 \\
\hline Unknown & 237 & 57.5 \\
\hline \multicolumn{3}{|l|}{ Additional features of aggressors } \\
\hline History of psychiatric/metabolic disease & 80 & 20.0 \\
\hline Disorientation & 27 & 6.5 \\
\hline Confusion & 20 & 4.8 \\
\hline Intoxication & 17 & 4.1 \\
\hline \multicolumn{3}{|l|}{ Neurological diseases } \\
\hline (Alzheimer's disease/dementia) & 84 & 20.3 \\
\hline Drug/alcohol/substance abuse & 209 & 50.5 \\
\hline Pain/anxiety & 79 & 19.1 \\
\hline History of violence & 90 & 21.8 \\
\hline
\end{tabular}

Table 4. Causes of increased violence against healthcare workers according to physicians

\begin{tabular}{|l|c|c|}
\hline Variables & $\mathbf{n}$ & (\%) \\
\hline Health policies & 490 & 97.0 \\
\hline $\begin{array}{l}\text { Publications that undermine } \\
\text { the dignity of physicians }\end{array}$ & 472 & 93.5 \\
\hline $\begin{array}{l}\text { Increase in society's expectations } \\
\begin{array}{l}\text { Ignorance or misinterpretation } \\
\text { of patient rights }\end{array}\end{array}$ & 328 & 65.0 \\
\hline Economic problems & 220 & 63.9 \\
\hline Problems related to education and culture & 406 & 80.4 \\
\hline Devolution of beliefs and values & 265 & 52.5 \\
\hline Intolerance & 423 & 83.8 \\
\hline Lack of authority and legal gaps & 407 & 80.6 \\
\hline
\end{tabular}

Four hundred and fourteen individuals who stated that they were exposed to violence ( $100 \%, \mathrm{n}=414)$ were exposed to verbal violence; $74.4 \%(n=308)$ were exposed to physical violence, and $28.3 \%(n=117)$ were exposed to sexual violence. Exposure to physical violence was significantly higher in men $\left(x^{2}=3.940 ; p=0.047\right)$. No significant difference was observed between genders in other types of violence ( $p>0.05)$.

During their entire career, 216 (52.2\%) participants faced violence 1-5 times, 113 (27.3\%) faced violence 5-10 times, and 151 (36.5\%) faced violence $>10$ times. The median working periods of the participants were significantly different with regard to how many times they have faced violence $\left(x^{2}=40.142 ; p<0.001\right)$. The duration of profession of participants who faced violence $>10$ times throughout their career was observed to be longer than those who faced violence 1-5 and 5-10 times ( $p<0.001$ and $p<0.001$, respectively).

In total, 85 (20.5\%) individuals stated that they were exposed to violence during working hours between 8:00 and 17:00, whereas 329 $(79.5 \%)$ individuals stated that they were exposed to violence during afterhours between 17:00 and 8:00 (night shifts).

With regard to how many patients were examined by the participants during a shift ( $24 \mathrm{~h}$ ) in the emergency department, we found that $17.6 \%(n=88)$ of the physicians examined $<50$ patients, $31.5 \%(n=157)$ examined 50-100, 22.8\% ( $n=114)$ examined $100-200$, and $28.1 \%$ $(n=140)$ examined $>200$ patients during a shift. No relationship was observed between the number of patients examined during a shift and the exposure to violence $\left(X^{2}=5.263 ; p=0.511\right)$.

With regard to the negative effects of facing violence, $60.6 \%(n=251)$ of the participants stated that their social life was negatively affected, $54.8 \%(n=227)$ reported a decrease in job satisfaction or interest toward their profession, and $53.4 \%(n=221)$ stated a decline in work quality (Table 2). No significant differences between sex and the specified individual effects of violence were observed $(p>0.05)$.

With regard to attackers, 336 (81.6\%) were male, and most of them were aged between 25 and 40 years (Table 3). When we compared the types of violence and the gender of the attackers, we found that only exposure to sexual violence was associated with the gender of the attacker. Among the victims of sexual violence, $75.0 \%$ $(n=87)$ stated that the aggressor was male $\left(x^{2}=4.609 ; p=0.032\right)$. No significant relationship was observed between the type of violence and the other characteristics of the aggressors ( $p>0.05$ ).

The number of participants who believe that health policies in Turkey triggered the increase of violence against healthcare workers in the society was 490 (97.0\%). Two hundred and twenty (43.6\%) participants attributed this increase primarily to the economic problems in the society (Table 4).

\section{Discussion}

The rate of exposure to violence among healthcare workers was high in several studies. Gokce et al. (5) reported the frequency of physicians' exposure to violence as $71.4 \%$, whereas Behnam et al. (6) reported this rate as $78 \%$. According to the Violence against 
Physicians Workshop report of the Istanbul Chamber of Physicians in 2009, the ratio of healthcare workers who witnessed violence throughout their career was reported as $96 \%$, and $64 \%$ of them faced violence at least once during their career (7). In our study, the ratio of those who witnessed violence against healthcare workers was $98.4 \%$, and the ratio of those who were exposed to violence throughout their career was $82.5 \%$. These results reveal that violence against healthcare workers has been increasing since 2006 .

A majority of studies show that verbal violence is experienced more often than other forms of violence. According to the report of the Violence against Physicians Workshop of the Istanbul Chamber of Physicians, the rate of healthcare workers who experienced verbal violence was reported to be $100 \%$, and the rate of those who experienced physical violence was $88 \%$ (7). Similarly, in a study conducted by Behnam et al. (6), the rate of exposure to verbal violence was higher than that of physical violence. In a study by Crilly et al. (8), the ratio of verbal violence (53\%) was also significantly higher. The results of our study were in accordance with literature, indicating that physicians' rate of exposure to verbal violence was higher than other kinds of violence.

A statistically significant relationship was obtained between exposure to violence and job title. In 2006, Ayranci et al. (9) reported that general practitioners, followed by resident doctors, are exposed to violence most frequently. In our study, $53.4 \%$ of the individuals who were victims of violence were resident physicians. In our opinion, the reasons why resident doctors are more exposed to violence may be: 1) they are not experienced enough to intuit and manage violence, 2) they have longer working hours, 3) they see greater numbers of patients, and 4) they spend more time with patients and their relatives.

Exposure to violence in the workplace leads to decreased motivation, performance, self-esteem, and dignity, and increased depressive symptoms, anxiety, and stress. May and Grubbs (10) reported that violence against healthcare workers leads to problems such as physical damage, abrasion, muscle pain, bone fractures, permanent disability, and emotional stress. In 2005, Kowalenko et al. (11) reported that $16 \%$ of the physicians consider changing hospitals; $1 \%$ of them changed their hospital, and $19 \%$ stated that they want to leave the emergency department because of the violence they experienced during their career. The workshop report on the Violence against Physicians of the Istanbul Chamber of Physicians indicated that burnout, adjustment disorder, anxiety, acute stress disorder, and posttraumatic stress disorder are observed in physicians because of exposure to violence (7). Gates reported that healthcare workers experience problems in concentrating and in controlling emotions after violence (3). In our study, we found that healthcare workers experienced problems such as loss of morale and motivation, decreased job satisfaction, decreased job quality, traumatic stress disorder, anxiety, panic, and adverse effects on social life because of exposure to violence in their workplace.

Individuals with a tendency to aggressive behavior usually have lower socio-economic status, problems with authority, and have experienced legal issues previously. A majority of these individuals are alcoholics or drug addicts. In addition, individuals with metabolic, neurological (e.g., Alzheimer's disease, epilepsy, and dementia), and psychiatric disorders have a higher tendency to violence (12). In our study, $58.6 \%$ of the attackers had low socio-economic status. In addition, $50.5 \%(n=209)$ of the physicians who were exposed to violence stated that the attackers used drugs, alcohol, or other substances, $21.8 \%(n=90)$ stated that the attackers had a history of violence, $20.3 \%(n=84)$ stated that the attackers had neurological disorders (Alzheimer's disease and dementia), and 20\% $(n=83)$ stated that the attackers had psychiatric disorders. No statistically significant difference was detected between these conditions and the occurrence of violence.

Several studies have shown that social reasons were effective in the increase of violence against healthcare workers. In the Report on Violence in the Healthcare Sector published by the Gaziantep-Kilis Chamber of Physicians in 2008, factors such as ethnic and religious tension, economic problems, cultural level of the society, and devolutions experienced in the beliefs and values in the society have been blamed for the increase of tendency to violence in Turkey (13). In the Report on Violence against Healthcare Workers and Perception of Violence published by Isparta, Burdur Chamber of Physicians in 2008, economic, social, and cultural problems are reported to cause the spread of violence in the society, and misleading of media and individuals' distrustfulness to the legal system are stated to increase the susceptibility to violence (14). In our study, $97 \%$ of the participants blamed health policies for the increase of violence in the society, 93\% blamed publications that erode the physicians' reputation, $80 \%$ referred to educational and cultural issues, and $83 \%$ referred to lack of tolerance.

The results of our study reveal that violence toward healthcare workers has been increasing in recent years, and a majority of healthcare workers either witness or experience violence at least once in their career. Physicians attribute this increasing tendency to the health policies that discredit the hard work of the physicians.

\section{Study limitations}

The e-mail response rate was $20.9 \%$ in our study, limiting the generalisability of our results to all emergency physicians in Turkey.

\section{Conclusion}

Violence against physicians and other healthcare professionals has become a global problem that affects public health. Therefore, precautions should be taken against violence as soon as possible, and a more secure and peaceful working environment should be provided for healthcare professionals.

We believe that the present study will help future studies to resolve problems related to this issue and enhance efforts to maintain a more secure work environment.

Ethics Committee Approval: Ethics committee approval was received for this study from the Ethics Committee of Yildirim Beyazit University School of Medicine (Date: 29.4.2013- Number:56).

Informed Consent: Written informed consent was obtained from doctors who participated in this study. 
Peer-review: Externally peer-reviewed.

Author Contributions: Concept - B.O., F.I, H.S.K., G.P.G., A.S., G.K.C.; Design - B.O., F.I., H.S.K., G.P.G., A.S., G.K.C.; Supervision - B.O., F.I., H.S.K., G.P.G., A.S., G.K.C.; Resources - B.O., F.I., H.S.K., G.P.G., A.S., G.K.C.; Materials - B.O., F.I, H.S.K., G.P.G., A.S., G.K.C.; Data Collection and/or Processing - B.O., F.I., H.S.K., G.P.G., A.S., G.K.C.; Analysis and/or Interpretation - B.O., F.I., H.S.K., G.P.G., A.S., G.K.C.; Literature Search - B.O., F.I, H.S.K., G.P.G., A.S., G.K.C.; Writing Manuscript - B.O., F.I., H.S.K., G.P.G., A.S., G.K.C.; Critical Review - B.O., F.I., H.S.K., G.P.G., A.S., G.K.C.; Other - B.O., F.I., H.S.K., G.P.G., A.S., G.K.C.

Conflict of Interest: The authors have no conflict of interest to declare.

Financial Disclosure: The authors declared that this study has received no financial support.

\section{References}

1. Yves M. La Violence. 1st ed. Paris: Presses Universitaires De France; 1988.

2. Annagur B. Violence towards health care staff: risk factors, aftereffects, evaluation and prevention. Current Approaches in Psychiatry. 2010; 2: 161-73.

3. Gates DM. Workplace violence. AAOHN J. 1995; 43: 536-43. [CrossRef]

4. Warshaw LJ. Workplace violence: preventive and interventive strategies. J Occup Environ Med. 1996; 38: 993-1006. [CrossRef]

5. Gokce T, Dundar C. The Frequency of exposing to violence and its effects on state and trait anxiety levels among the doctors and nurses working in Samsun Psychiatry Hospital. Journal of Inonu University Medical Faculty. 2008; 15: 25-8.
6. Behnam M, Tillotson RD, Davis SM, Hobbs GR. Violence: Recognition, Management, and Prevention. Violence in The Emergency Department: A National Survey Of Emergency Medicine Residents and Attending Physicians. J Emerg Med. 2011; 40: 565-79. [CrossRef]

7. Ogan $\mathrm{H}$, editor. Hekime Yonelik Siddet Calistayi Kitabi. [ìnternet]. İstanbul: İstanubul tabip odasi yayinlari; 2009. Available from: http://www.ttb. org. tr/siddet/images/file/itocalistay.pdf

8. Crilly J, Chaboyer W, Creedy D. Violence towards emergency department nurses by patients. Accid Emerg Nurs. 2004; 12: 67-73 [CrossRef]

9. Ayranci U, Yenilmez C, Gunay Y, Kaptanoglu C. The frequency of being exposed to violence in the various health institutions and health profession groups. Anatol J Psychiatr. 2002; 3: 147-54.

10. May DD, Grubbs L. The extent, nature, and precipitating factors of nurses assault among three groups of registered nurses in a regional medical center. J Emerg Nurs. 2001; 28: 11-7. [CrossRef]

11. Kowalenko $T$, Walters $B$, Khare $R$, Compton $S$. Workplace Violence: $A$ Survey of Emergency Physicians in the State of Michigan. Ann Emerg Med. 2005; 46: 142-7. [CrossRef]

12. Volavka J. The neurobiology of violence: An update. J Neuropsychiatry Clin Neurosci. 1999; 11: 307-14. [CrossRef]

13. Adas EB, Elbek O, Bakir K, editors. Hekimlere Yonelik Siddet ve Hekimlerin Siddet Algisi. [internet]. Gaziantep: Gaziantep Kilis Tabip Odasi yayinlari; 2008. Available from: http://www.ttb.org.tr/siddet/images/file/ gaziantepsiddet.pdf

14. Aydin M. İsparta-Burdur Saglik Calisanlarina Yonelik Siddet ve Siddet Algisi. Available from: www.ttb.org.tr/siddet/images/stories/file/rapor/ isparta.doc 